\title{
Association of neutrophil/lymphocyte ratio with obstructive coronary artery disease and coronary artery calcium score detected by multislice computed tomography in type 2 diabetes mellitus patients
}

\author{
This article was published in the following Dove Press journal: \\ Patient Preference and Adherence \\ 17 July 2015 \\ Number of times this article has been viewed
}

\author{
Fatih Aygün' \\ Duran $\mathrm{Efe}^{2}$ \\ 'Department of Cardiovascular \\ Surgery, Konya Medical and \\ Research Center, Bașkent University, \\ ${ }^{2}$ Department of Radiology, Faculty \\ of Medicine, Mevlana University, \\ Konya, Turkey
}

\begin{abstract}
Objective: The aim of the present study was to investigate the association of neutrophil/ lymphocyte ratio (NLR) with coronary artery calcium score (CACS) and obstructive coronary artery disease (CAD) detected by multislice computed tomography (MSCT) angiography in type 2 diabetes mellitus (T2DM) patients.

Methods: Two hundred and ninety-two T2DM patients, who were either asymptomatic or symptomatic (but noncharacteristic) for coronary artery disease (CAD) and underwent MSCT angiography in our clinic between May 2009 and June 2014, were enrolled. All patients were divided into two groups according to their mean NLR values. Patients with NLR $\leq 2.05$ were assigned to Group 1 and patients with NLR $>2.05$ were assigned to Group 2. The association of NLR with CACS and obstructive CAD, which were detected by MSCT angiography, was investigated in T2DM patients.

Results: According to the Agatston scoring method, the mean CACS was $129.5 \pm 209.8 \mathrm{Au}$ in Group 1 and 290.3 $\pm 399.6 \mathrm{Au}$ in Group $2(P<0.001)$. Obstructive CAD was detected in 40 (26.8\%) patients in Group 1 and in $56(39.2 \%)$ patients in Group $2(P<0.05, P=0.021)$.

Conclusion: The rate of obstructive CAD was significantly higher in the T2DM patients with NLR $>2.05$ than that in the T2DM patients with NLR $\leq 2.05$. In addition, the CACS was also significantly higher in the T2DM patients with NLR $>2.05$ than that in the T2DM patients with NLR $\leq 2.05$.
\end{abstract}

Keywords: neutrophil, lymphocytes, coronary atherosclerosis, coronary calcium score, multislice computed tomography, type 2 diabetes mellitus

\section{Introduction}

Type 2 diabetes mellitus (T2DM) is a prevalent disease affecting many people all over the world and its worldwide prevalence was 6.6\% in 2010. ${ }^{1}$ Cardiovascular diseases are the leading causes of morbidity and mortality in diabetic patients. ${ }^{2}$ A positive association has been defined between atherosclerosis and various inflammatory conditions such as T2DM, hypertension (HT), obesity, and smoking. ${ }^{3}$

The number of persons suffering from T2DM is expected to approximately double in the next 25 years. The count of persons with T2DM will be increasing from 175 million individuals in 2000 to 353 million in $2030 .{ }^{4}$ T2DM is the major health problem encountered by the developing countries. If T2DM can be early diagnosed, T2DM-related diseases such as cardiovascular disease and systemic complications can be prevented. ${ }^{5}$ Atherosclerosis is a T2DM-related problem, and it is a source of cardiovascular disease. ${ }^{6}$
Correspondence: Fatih Aygün Hocacihan Mahalle Saray Cad No I, 42000 Selçuklu, Konya, Turkey $\mathrm{Tel}+9033232294$ I0

Fax +903323229419 Email fatihaygun@ttmail.com 
Metabolic changes due to T2DM can impair the vascular walls, and this condition plays an important role in atherosclerotic plaque development. ${ }^{6}$

American Diabetes Association defined prediabetes as a metabolic clinical condition that leads to predisposition for the future development of T2DM. ${ }^{7}$ Impaired fasting glucose (IFG) and/or impared glucose tolerance (IGT) are two main conditions of prediabetes. IFG is defined as a fasting plasma glucose levels ranging from $100 \mathrm{mg} / \mathrm{dL}$ $(5.6 \mathrm{mmol} / \mathrm{L})$ to $125 \mathrm{mg} / \mathrm{dL}(6.9 \mathrm{mmol} / \mathrm{L})$. IGT as a condition characterized by 2 -hour values of plasma glucose in the oral glucose tolerance test ranging from $140 \mathrm{mg} / \mathrm{dL}$ $(7.8 \mathrm{mmol} / \mathrm{L})$ to $199 \mathrm{mg} / \mathrm{dL}(11.0 \mathrm{mmol} / \mathrm{L})$. Additionally a glycated hemoglobin (HbA1C) plasma levels ranging from $5.7 \%$ to $6.4 \%$ is further considered as a prediabetic condition. $^{7}$

T2DM persons who have developed cardiac dysfunction have several molecular signaling pathways that were broken. ${ }^{8,9}$ Hyperinsulinemia, hyperglycemia, and insulin resistance affect oxidative stress molecules, and oxidative stress molecules increase may start initial damages to cardiac cells. ${ }^{10,11}$ The disorder of oxidative metabolism increases free fatty acids circulation and lipid metabolism, and this process ends up with lipid accumulation and lipotoxicity in the heart. ${ }^{12}$

Inflammation plays an important role in all stages of coronary artery disease (CAD). ${ }^{13}$ Atherosclerosis is a complex inflammatory disease. ${ }^{14}$ Leukocytes make substantial contribution to this inflammatory process. ${ }^{15}$ In several prospective studies, a positive correlation has been demonstrated between total and different leukocyte counts and future cardiovascular events in healthy subjects. ${ }^{16,17}$ Recently, neutrophil/ leukocyte ratio (NLR) has appeared as a new inflammatory biomarker. ${ }^{18}$

In one study, NLR was higher in patients with hemodynamically significant coronary artery stenosis. NLR was found to be an independent predicting factor for hemodynamically significant coronary artery stenosis as measured by fractional flow reserve (FFR). ${ }^{19}$

Another study shows that platelet count, white blood cell count, creatinine, glycemia, uric acid, and C-reactive protein levels affected NLR. NLR was inversely related to total cholesterol, triglycerides, and hemoglobin. The NLR was associated with multiple CAD, anterior descending CAD, right $\mathrm{CAD}$, branch lesions of circumflex $\mathrm{CAD}$, coronary artery stenosis percentage, coronary artery calcification, and coronary artery trombosis. It was shown that NLR was associated with CAD and severity. ${ }^{20}$
One study shows that there is a relationship between neutrophil gelatinase-associated lipocalin (NGAL) and the degree of aortic stiffness. Patients with noncritical CAD have higher degree of aortic stiffness and NGAL level. According to this study, NGAL can be used as a tool for risk stratification in patients with noncritical CAD. ${ }^{21}$

Moro-Garcia et al have shown that the patients who have acute coronary syndrome have higher immune response. ${ }^{22}$

There is a strong parallelism between coronary artery wall calcification and atherosclerotic CAD. ${ }^{23}$ It is known that detection of amount and distribution of coronary artery calcification and performing coronary artery calcium scoring (CACS) are important parameters for the prediction of cardiovascular risk. ${ }^{24-26}$ Multislice computed tomography (MSCT) coronary angiography is considered as a noninvasive modality in detecting and classifying CAD. ${ }^{27,28}$

The aim of the present study was to investigate the association of NLR with CACS and obstructive CAD detected by MSCT angiography in type 2 diabetic patients.

\section{Methods}

\section{Clinical characteristics of patients}

The present study comprised 292 T2DM patients, who were either asymptomatic or symptomatic (but most of them were noncharacteristic) for coronary artery disease (CAD) and had undergone MSCT angiography in our clinic. The study comprised patients who had nonspecific or stable angina and were in New York Heart Association class II or lower and admitted to the Cardiology or Internal Medicine Polyclinic. The patients did not have any complaints except chest pain. They had no autoimmune disease and were found to have no infection. The patients who had WBC count out of the normal range (4,000-12,000 cells/ $\mu \mathrm{L})$, acute infection, autoimmunological diseases, and any other disease (such as urinary system infection, cholecystitis) that could affect WBC count were excluded. Data were collected retrospectively, and the approval of the Ethics Committee (Medical School, Selçuk University, Konya, Turkey) was obtained. Our study was designed and managed according to the Declaration of Helsinki.

\section{Cardiovascular risk factors}

All participants were explored in terms of risk factors for CAD including smoking, HT, T2DM, hyperlipidemia, and family history of CAD. Smoking related to ischemic CAD. People who are living in our country use cigarette.

T2DM was defined in patients with $\mathrm{HbA}_{1 \mathrm{c}}$ level of $\geq 6.5 \%$ (48 mmol/L) and a fasting plasma glucose level of $\geq 7.0 \mathrm{mmol} / \mathrm{L}(126 \mathrm{mg} / \mathrm{dL})$. Serum glucose and $\mathrm{HbA}_{1 \mathrm{c}}$ 
levels were detected using Cobast integra 800 (Hoffman-La Roche Ltd., Basel, Switzerland).

HT as medical term is characterized by systolic tension $\geq 140 \mathrm{mmHg}$ or diastolic tension $\geq 90 \mathrm{mmHg}$ in adult persons ( $>18$ years of age). These measurements have to be done on two different days and using blood pressure tools calibrated.

Dyslipidemia was defined in patients with a fasting total cholesterol serum level of $\geq 240 \mathrm{mg} / \mathrm{dL}$, serum level of triglyceride $\geq 200 \mathrm{mg} / \mathrm{dL}$, low-density lipoprotein (LDL) cholesterol $\geq 160 \mathrm{mg} / \mathrm{dL}$, and/or high-density lipoprotein (HDL) cholesterol $<40 \mathrm{mg} / \mathrm{dL}$ and in patients receiving or not receiving medical therapy for dyslipidemia. ${ }^{29}$ Serum cholesterol levels were detected using Cobast integra 800 (Hoffman-La Roche Ltd.).

Before computerized tomography scanning, height (Human scale; NAN Tarti Co., Turkey) and weight (TANITA Body Composition Analyzer; TANITA Corporation, Japan) of the patients were measured and their body mass indexes (BMIs) were calculated. Patients with BMI $<25 \mathrm{~kg} / \mathrm{m}^{2}$ were considered to have normal weight, those with BMI between $25 \mathrm{~kg} / \mathrm{m}^{2}$ and $30 \mathrm{~kg} / \mathrm{m}^{2}$ were considered overweight, and those with BMI $\geq 30 \mathrm{~kg} / \mathrm{m}^{2}$ were considered obese.

\section{Coronary calcium scoring}

In the first step, all patients underwent noncontrast-enhanced computed tomography (CT) beginning from carina extending to the subdiaphragmatic level (Somatom Sensation 64; Siemens, Forchheim, Germany). On noncontrast-enhanced CT, calcified coronary artery plaques were explored on cardiac sections. CACS was performed using preexisting software in the device (Syngo CaScore, Siemens; Agatston scoring method).

Total CACS was the sum of calcium levels calculated in the left main coronary artery, in the left anterior descending coronary artery, in the circumflex coronary artery, and in the right coronary artery traces. Collected data were evaluated using the percentiles predefined according to the age and sex. ${ }^{30}$ Individual calcium scores were grouped as low ( $0-25$ percentile), moderate (25-75 percentile), and high (75-100 percentile).

\section{Multislice computed tomography image reconstruction and $C A D$ evaluation}

In the second step, all patients underwent MSCT angiography using Somatom Sensation 64 tomography device (Siemens), and scanning parameters were selected as follows: gantry rotation time $330 \mathrm{~ms}$; tube voltage $120 \mathrm{~kW}$; $250 \mathrm{~mA}$; and detector collimation $0.6 \mathrm{~mm}$. Images were obtained in a single breath within approximately 8.4-13.1 seconds in craniocaudal direction from carina to subcostal level. During
MSCT angiography, 80-110 mL (based on the patient's weight) of nonionic contrast agent (Iomeron 400; Bracco s.p.a., Milan, Italy) was administered through antecubital vein at a speed of $5.0 \mathrm{~mL} / \mathrm{s}$ followed by $40 \mathrm{~mL}$ isotonic bolus. Automatic peak contrasting density through ascending aorta was determined to be +140 Hounsfield units. Reconstructions were obtained from the images on $0.6 \mathrm{~mm}$ sections increasing them by $0.6 \mathrm{~mm}$ according to the retrospective electrocardiography-gating technique. Images in multiplanar reformats and three-dimensional volume rendering format were created from thin axial sections, and anatomy of coronary artery was evaluated.

All segments of coronary arteries were investigated visually. Patients were divided into groups according to the degree of coronary artery obstruction as normal (without or insignificant plaque), non-obstructive CAD (non-obsCAD; degree of obstruction $<50 \%$ with at least one plaque), and obstructive CAD (obsCAD; degree of obstruction $\geq 50 \%$ with at least one plaque) (Figures 1 and 2). MSCT angiography was performed by radiologists, cardiovascular surgeons, and cardiologists. MSCT angiography examinations were performed by specialists who were blinded to NLR results.

\section{White blood cell count and neutrophil/ lymphocyte ratio}

White blood cell and different subtype counts were obtained using automated differential leukocyte counter Sysmex KX-21N (TOA Medical Electronics, Kobe, Japan). Patients

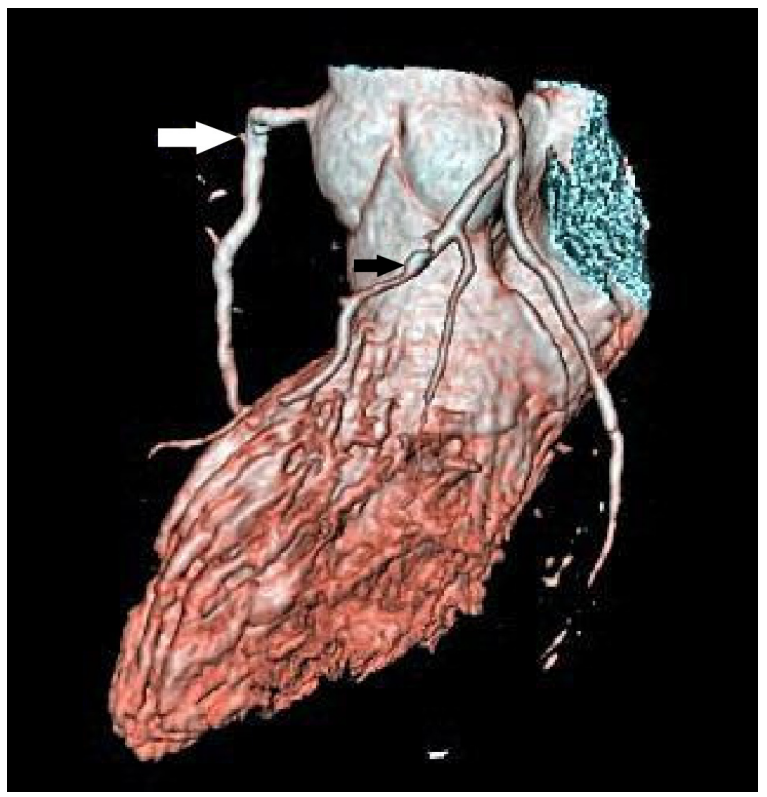

Figure I Right coronary artery with plaque (white arrow) and left anterior descending coronary artery with plaque (black arrow). 


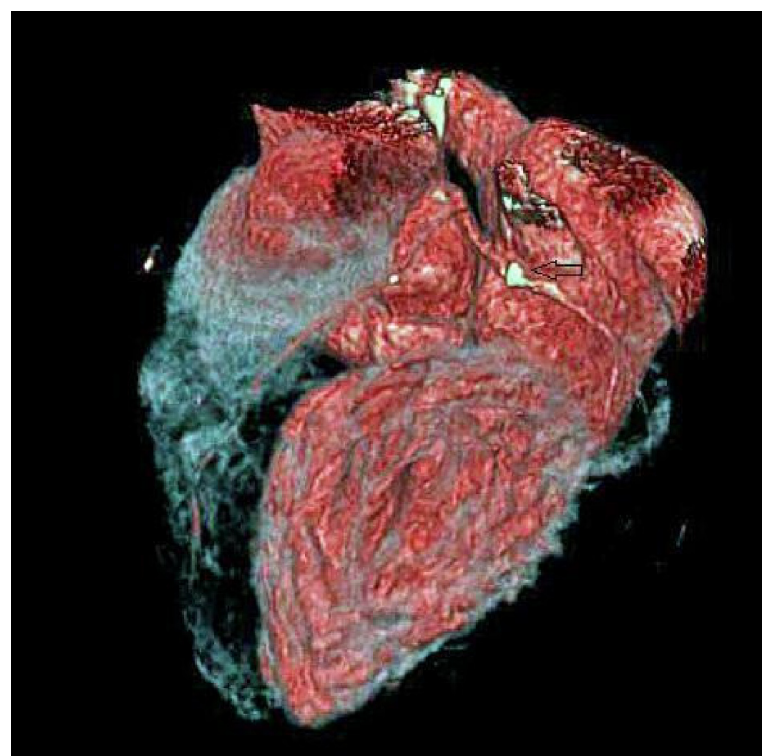

Figure 2 Circumferential coronary artery with plaque (arrow).

were divided into two groups according to their mean NLR values as Group 1 having NLR $\leq 2.05$ and Group 2 having NLR $>2.05$. Groups were formed according to the mean values of the study population. MSCT angiography was performed in a short time (1-3 days) after WBC count measurement.

\section{Statistical analysis}

Statistical analyses were performed using the Statistical Package for the Social Sciences program (SPSS Inc., Chicago, IL, USA). Statistical significance of nonparametric data between the groups was analyzed by Pearson's chi-squared test. Parametric data were expressed as minimum, maximum, and mean \pm standard deviation, and statistical significance of parametric data between the groups was analyzed by independent Student's $t$-test. The result was considered statistically significant if two-tailed $P$-value was lower than 0.05 $(P<0.05)$. The relationship of obsCAD with CACS and NLR was found to be significant using multivariate analysis.

Binary logistic regression analysis was performed to assess the independent predictors of obsCAD. All variables that were found significant in univariate analysis were included in the model of logistic regression model, and the results are shown as an odds ratio with $95 \%$ confidence intervals. A two-tailed $P<0.05$ was considered as statistically significant.

The relationship among NLR, CACS, and obsCAD were investigated using one-way analysis of variance (ANOVA) and post hoc analysis, which are two of the multivariate analysis tests. A two-tailed $P$-value of $<0.05$ was considered statistically significant. Multivariate analysis (one-way ANOVA) was performed on groups that were separated as normal, non-obsCAD, and obsCAD. Persons who were grouped as normal, non-obsCAD, and obsCAD were different in terms of NLR $(P<0.05, P=0.04)$ and calcium scoring $(P<0.01)$.

\section{Results}

In our study, we saw that groups are similar with regard to some parameters such as age and sex. But Group 2 has higher rates of HT $(P=0.022, P<0.05)$, CACS $(P<0.001)$, and obsCAD $(P=0.021, P<0.05)$ (Table 1). Group 2 included persons who have high NLR. Statistical analysis was adjusted to the angle of these factors in Table 2. We found statistical significance for CACS in Group 2, which has high CACS $(P<0.001)$. The persons who are using antiHT agents were statistically similar according to drug difference in both groups $(P>0.05)$.

\section{The sex differences between two groups regarding clinical characteristics}

In the males of Group 1, the mean NLR was $1.55 \pm 0.3$, the mean age was $54.3 \pm 8.8$ years, and the mean CACS according to the Agatston scoring was $131.7 \pm 204.8 \mathrm{Au}$, whereas the mean value of serum $\mathrm{HbA}_{1 \mathrm{c}}$ was $7.5 \pm 1.8$, fasting blood glucose was $130.1 \pm 55.1 \mathrm{mg} / \mathrm{dL}$, serum triglyceride was $183.2 \pm 132.2 \mathrm{mg} / \mathrm{dL}$, serum HDL was $45.1 \pm 14.5 \mathrm{mg} / \mathrm{dL}$, and serum LDL was $116.5 \pm 35.7 \mathrm{mg} / \mathrm{dL}$. Of the males, $28(21.5 \%)$ were obese, $47(36.2 \%)$ were smokers, 33 (25.4\%) had obsCAD, 73 (56.2\%) had HT, 68 (52.3\%) had hyperlipidemia, $54(41.5 \%)$ were receiving statin, and 85 (65.4\%) were receiving antidiabetic agent (Figure 3).

In the females of Group 1, the mean NLR was 1.6 \pm 0.33 , the mean age was $67.1 \pm 7.3$ years, and the mean coronary artery calcium score (CACS) according to the Agatston scoring was $114 \pm 247.0 \mathrm{Au}$, whereas the mean value of serum $\mathrm{HbA}_{1 \mathrm{c}}$ was 7.9 \pm 2.8 , fasting blood glucose was $116.6 \pm 35.5 \mathrm{mg} / \mathrm{dL}$, serum triglyceride was $150.4 \pm 65.2 \mathrm{mg} / \mathrm{dL}$, serum HDL was $57.5 \pm 20.8 \mathrm{mg} / \mathrm{dL}$, and serum LDL was $119.4 \pm 28.8 \mathrm{mg} / \mathrm{dL}$. Seven $(36.8 \%$ ) females were obese, and none of the females were smokers. Of the females, seven $(36.8 \%)$ had obsCAD, $13(68.4 \%)$ had HT, eleven (57.9\%) had hyperlipidemia, eleven (57.9\%) were receiving statin, and nine (47.4\%) were receiving antidiabetic agent (Figure 4).

In the males of Group 2, the mean NLR was $2.4 \pm 0.34$, the mean age was $55.6 \pm 11.2$ years, and the mean CACS according to the Agatston scoring was $309.8 \pm 418.0 \mathrm{Au}$, whereas the mean 
Table I Statistical data for two groups according to NLR

\begin{tabular}{|c|c|c|c|}
\hline & $\begin{array}{l}\text { Group I }(n=\mid 49) \\
(N L R \leq 2.05)\end{array}$ & $\begin{array}{l}\text { Group } 2(n=143) \\
(N L R>2.05)\end{array}$ & $P$-value \\
\hline NLR & $1.5 \pm 0.3$ & $2.5 \pm 0.3$ & $<0.00 I^{*}$ \\
\hline Age, years $( \pm S D)$ & $55.9 \pm 9.6$ & $56.7 \pm 12.2$ & $0.520 *$ \\
\hline Sex (male) & I 30 (87.2\%) & I 28 (89.5\%) & $0.547 * *$ \\
\hline Smoking & 47 (31.5\%) & $50(35 \%)$ & $0.535 * *$ \\
\hline Familial history & 17 (1 I.4\%) & $19(13.3 \%)$ & $0.626 * *$ \\
\hline Body mass index normal weight & $32(21.5 \%)$ & $18(12.6 \%)$ & \\
\hline Overweight & 82 (55\%) & $88(61.5 \%)$ & $0.131 * *$ \\
\hline Obese & $35(23.5 \%)$ & 37 (25.9\%) & \\
\hline Blood glucose level (starving) (mg/dL) & $128.4 \pm 53.1$ & $126.8 \pm 40.5$ & $0.773^{*}$ \\
\hline $\mathrm{HbA}_{\mathrm{Ic}}$ (last 6 months) $(\mathrm{mg} / \mathrm{dL})$ & $7.5 \pm 0.9$ & $7.6 \pm 2.2$ & $0.660^{*}$ \\
\hline Cholesterol (mg/dL) & $194.6 \pm 1.4$ & $195 \pm 36.8$ & $0.935^{*}$ \\
\hline Triglyceride (mg/dL) & $179 \pm 75.4$ & $162.8 \pm 75.4$ & $0.186 *$ \\
\hline High-density lipoprotein-C (mg/dL) & $46.7 \pm 126$ & $47.7 \pm 14.5$ & $0.572^{*}$ \\
\hline Low-density lipoprotein-C (mg/dL) & $116.9 \pm 34.8$ & $118.2 \pm 30.1$ & $0.729 *$ \\
\hline Aspartate aminotransferase (U/L) & $24.7 \pm 13.6$ & $22.6 \pm 10.3$ & $0.14 I^{*}$ \\
\hline Alanine aminotransferase (U/L) & $32.8 \pm 25$ & $32.7 \pm 23.3$ & $0.978^{*}$ \\
\hline Hyperlipidemia & 79 (53\%) & $83(58 \%)$ & $0.388 * *$ \\
\hline Hypertension & $86(57.7 \%)$ & 101 (70.6\%) & $0.022 * *$ \\
\hline \multicolumn{4}{|l|}{ Antihypertension agents } \\
\hline ACE inhibitors & 29 (33.7\%) & $32(31.7 \%)$ & $0.977^{* *}$ \\
\hline Beta blockers & 17 (19.8\%) & 20 (19.8\%) & \\
\hline Calcium-channel blockers & $29(33.7 \%)$ & $37(36.6 \%)$ & \\
\hline Angiotensin receptor blockers & II (12.8\%) & $12(11.9 \%)$ & \\
\hline Statin use & $65(43.6 \%)$ & $67(46.9 \%)$ & $0.579 * *$ \\
\hline Antidiabetic agent & $94(63.1 \%)$ & $96(67.1 \%)$ & $0.469 * *$ \\
\hline Calcium scoring $(\mathrm{Au})$ & $129.5 \pm 209.8$ & $290.3 \pm 399.6$ & $<0.00 I^{*}$ \\
\hline \multicolumn{4}{|l|}{ CAD disease } \\
\hline Normal + non-obsCAD & 109 (73.2\%) & 87 (60.9\%) & \\
\hline ObsCAD & $40(26.8 \%)$ & $56(39.2 \%)$ & $0.021 * *$ \\
\hline
\end{tabular}

Notes: *P-value was presented as a result of Student's $t$-test. **P-value was presented as a result of Pearson's chi-squared test.

Abbreviations: NLR, neutrophil/lymphocyte ratio; SD, standard deviation; $\mathrm{HbA}_{\mathrm{Ic}}$, glycosylated hemoglobin; ACE, angiotensin converting enzyme; CAD, coronary artery disease; non-obs, non-obstructive; obs, obstructive.

value of serum $\mathrm{HbA}_{1 \mathrm{c}}$ was 7.6 \pm 2.3 , fasting blood glucose was $128.2 \pm 42.1 \mathrm{mg} / \mathrm{dL}$, serum triglyceride was $164.6 \pm 79.2 \mathrm{mg} / \mathrm{dL}$, serum HDL was $47.2 \pm 15.0 \mathrm{mg} / \mathrm{dL}$, and serum LDL was $117.7 \pm 30.2 \mathrm{mg} / \mathrm{dL}$. There were 34 (26.6\%) obese subjects and 47 (36.7\%) smokers; 51 (39.8\%) had obsCAD, 86 (67.2\%) had HT, 74 (57.8\%) had hyperlipidemia, 61 (47.7\%) were receiving statin, and $84(65.6 \%)$ were receiving antidiabetic agent.

In the females of Group 2, the mean NLR was 2.6 \pm 0.39 , the mean age was $66.2 \pm 16.2$ years, and the mean CACS according to the Agatston scoring was $123.7 \pm 37.4 \mathrm{Au}$, whereas the mean value of serum $\mathrm{HbA}_{1 \mathrm{c}}$ was 7.6 \pm 0.95 , fasting blood glucose was $114.2 \pm 18.5 \mathrm{mg} / \mathrm{dL}$, serum triglyceride was $147 \pm 19.4 \mathrm{mg} / \mathrm{dL}$, serum HDL was $52.2 \pm 7.4 \mathrm{mg} / \mathrm{dL}$, and serum LDL was $122.7 \pm 29.8 \mathrm{mg} / \mathrm{dL}$. There were three $(20 \%)$ obese subjects and three (20\%) smokers; five $(33.3 \%)$ had obsCAD, 15 (100\%) had HT, nine (60\%) had hyperlipidemia, six (40\%) were receiving statin, and $12(80 \%)$ were receiving antidiabetic agent (Figure 5).

Of the 292 patients included in the groups, 162 (55.4\%) had diagnosis of hyperlipidemia. Of these patients, 132

Table 2 Binary logistic regression analysis was performed for hypertension and CACS, which showed statistically significant difference between the groups

\begin{tabular}{lllllll}
\hline & Unadjusted OR & $\mathbf{9 5 \%} \mathbf{C l}$ & P-value & Adjusted OR & 95\% Cl & P-value \\
\hline Hypertension & 3.246 & $1.231-8.557$ & 0.017 & - & - & - \\
Calcium scoring $(\mathrm{Au})$ & 1.009 & $1.007-1.012$ & $<0.001$ & 1.009 & $1.007-1.011$ & $<0.001$ \\
\hline
\end{tabular}

Abbreviations: $\mathrm{CACS}$, coronary artery calcium score; OR, odds ratio; $\mathrm{Cl}$, confidence interval. 


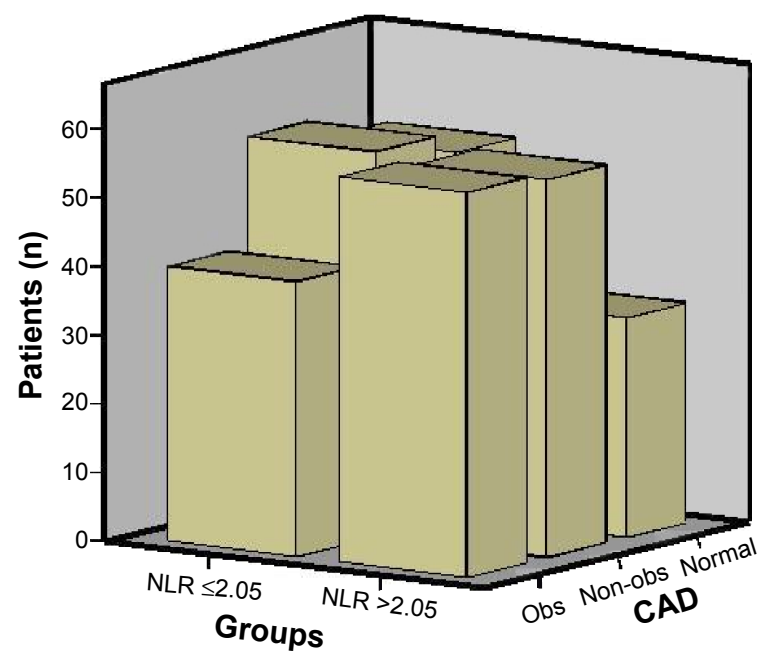

Figure 3 Coronary artery disease according to groups.

Abbreviations: CAD, coronary artery disease; obs, obstructive; NLR, neutrophil/ lymphocyte ratio; non-obs, non-obstructive; obs, obstructive.

were using statins and 30 discontinued their therapies due to statin-induced hypolipidemia.

\section{Discussion}

In the present study, the rate of obsCAD detected in MSCT angiography in Group 2 was significantly higher than in Group $1(P<0.05)$. Moreover, CACS was significantly higher in Group 2 than in Group $1(P<0.05)$. The relationship of obsCAD with CACS and NLR was found to be significant using multivariate analysis $(P=0.048, P<0.001)$.

MSCT has been proposed as a noninvasive method for detection and classification of coronary artery plaques. ${ }^{27,28,31}$ MSCT coronary angiography is an important tool to detect CAD in an early stage. In a study, MSCT angiography and

\section{NLR and CACS mean values}

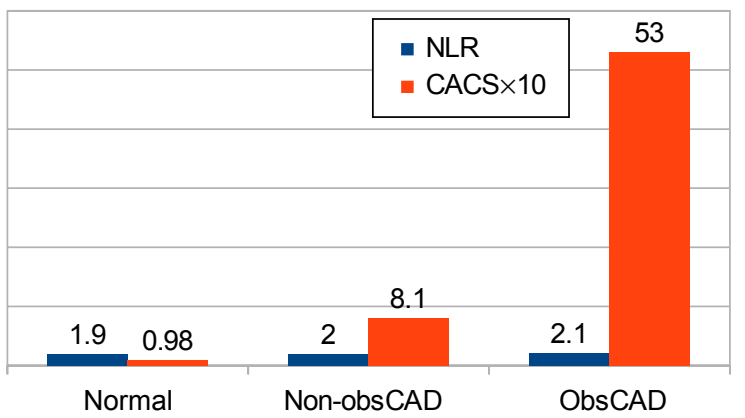

Figure 4 Multivariate analysis (one-way ANOVA) was performed on groups separated as normal, non-obsCAD, and obsCAD. Among persons who has either normal, or non-obsCAD, or obsCAD were different in terms of NLR $(P<0.05$, $P=0.04)$ and calcium scoring $(P<0.01)$.

Abbreviations: ANOVA, analysis of variance; non-obsCAD, non-obstructive coronary artery disease; obsCAD, obstructive coronary artery disease; NLR, neutrophil/ lymphocyte ratio; CACS, coronary artery calcium score.

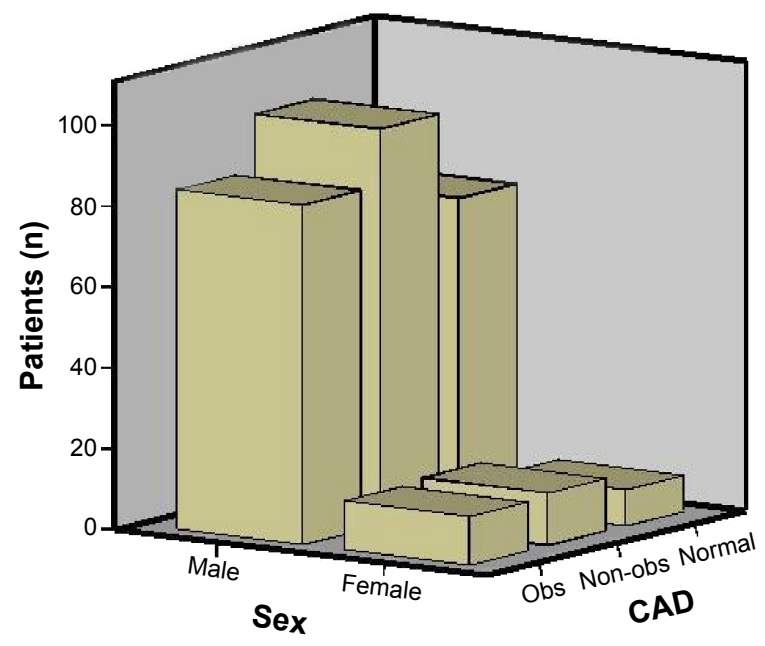

Figure 5 Coronary artery disease according to sex.

Abbreviations: CAD, coronary artery disease; obs, obstructive; non-obs, nonobstructive; obs, obstructive.

invasive coronary angiography have been compared in evaluating the coronary arteries and branches larger than $1.5 \mathrm{~mm}$ and the sensitivity and specificity of MSCT have been found to be $94 \%$ and $97 \%$, respectively. ${ }^{32}$

Risk of future coronary heart disease is increased as the total amount of calcium in the coronary arteries is increased. ${ }^{33}$ In a systematic study, while the prevalence of cardiovascular events in the patients with zero CACS has been found to be $0.56 \%$, its negative predictive value has been found to be as high as $99 \%{ }^{34}$ In some studies, the risk of significant coronary artery stenosis $(>50 \%)$ has been found to be lower than $3 \%$ by invasive coronary angiography in the patients with CACS lower than $100 \mathrm{Au} .{ }^{35}$ In our study, when the participants were divided into normal, non-obsCAD, obsCAD individuals, CACS was found to be $9.8 \pm 20.5 \mathrm{Au}$ in normal persons, $81.3 \pm 149.8 \mathrm{Au}$ in non-obsCAD persons, and 530.7 $\pm 376.5 \mathrm{Au}$ in obsCAD persons $(P<0.001)$.

Atherosclerosis is a multifactorial disease including HT, dyslipidemia, dysglycemia, smoking, and other cardiovascular risk factors. Recent studies have demonstrated that atherogenesis is not a simple passive injury caused by the serum lipids and other substances on the vascular wall, but an active inflammatory process. ${ }^{36}$ Leukocytes play a major role, either regenerative or pathogenic, in this inflammatory process. ${ }^{37}$ Functional molecules of inflammatory cells may lead to acute coronary syndrome by enhancing the progression of early atherogenic lesions. ${ }^{38}$ Recent studies have revealed that neutrophils participate in many steps ranging from the development to the rupture of atherosclerotic plaque. ${ }^{13-15,35,36}$ In our study, CACS shows that the accumulation of calcium in coronary artery and 
plaque development was found to be of high in Group 2 $($ NLR $>2.05)(P<0.001)$.

Some studies reported that hypercholesterolemia causes neutrophilia by enhancing the production of neutrophils and their passage from bone marrow into the circulation while decreasing their clearance. ${ }^{36}$ Our results did not show any differences among NLR groups regarding hyperlipidemia $(P>0.05)$ because the mean NLR was $2.04 \pm 0.53$ in the patients with hyperlipidemia, and it was $1.99 \pm 0.62$ in those with normal cholesterol level.

In a few studies, a significant correlation of fasting and postprandial blood glucose with WBC count has been reported. ${ }^{37}$ Two studies have also indicated a significant relation between neutrophil count and blood pressure. ${ }^{38}$ In our study, starving blood glucose level was found to be low in Group 1, which was found to be statistically insignificant, and in Group 2 with high NLR value has high $\mathrm{HbA}_{1 \mathrm{c}}$, which was statistically insignificant. The persons who have HT were higher in Group 2 than in Group 1 and is statistically significant $(P=0.022)$.

A ratio reflecting acute episode of inflammation (increase in neutrophil) and acute physiological stress (decrease in lymphocyte) has begun to be used recently. Gibson et al ${ }^{18}$ demonstrated NLR as a good indicator of inflammation. In acute coronary syndrome, lymphopenia can also be observed together with the increase in neutrophil. In the study by Furman et a ${ }^{39} \mathrm{WBC}$ and subtypes were found to be responsible for cardiovascular events and were emphasized as an indicator of inflammation. Kirtane et $\mathrm{a}^{40}$ showed that the increase in neutrophil level was associated with extent and short-term prognosis of myocardial damage in acute coronary syndrome. Thomson et $\mathrm{al}^{41}$ reported that the lymphopenia observed in acute coronary syndrome was associated with stress-induced cortisol release and that this was one of the early findings. In our study, the participants included were the persons who had no acute coronary syndrome, the persons who had no findings to coronary angiography application, and the persons who had suspicious laboratory results.

Papa et $\mathrm{al}^{42}$ emphasized NLR to be an independent predictor of cardiac events in patients with CAD. Horne et $\mathrm{al}^{43}$ confirmed NLR to be a predictor of mortality in patients with CAD. Gibson et $\mathrm{al}^{44}$ demonstrated NLR to be associated with the decrease in survival after coronary artery bypass grafting. Another study has indicated that NLR is an independent predictor of all-cause mortality in patients having percutaneous coronary intervention. ${ }^{45}$ In the study investigating the progression of coronary atherosclerosis, Kalay et $\mathrm{al}^{46}$ reported NLR as an important indicator. In our study, NLR was not compared with cardiac events as a predictor.
But according to our study, we can say that coronary artery plaque accumulation, which has potential for cardiac events, was found higher in Group 2 (NLR $>2.05$ ) and is statistically significant $(P<0.001)$.

Azab et al conducted a study in patients with T2DM and reported cardiac events to be more common in patients with high NLR. ${ }^{47}$ One of the current reviews, which was written by Balta et al reported that NLR is an indicator of inflammation, and it can be associated with vascular disease. ${ }^{48}$ Kurtul et al mentioned that NLR is independently associated with the severity of CAD in patients with non-ST segment elevation myocardial infarction. ${ }^{49}$ Tsai et al conducted a study in T2DM patients who have the risk of ischemic CAD and metabolic syndrome associated with peripheral leukocyte counts. They emphasized that NLR is the risk of ischemic cardiovascular disease, especially in T2DM patients who have metabolic syndrome..$^{50}$ In our study, we found that the count of obsCAD persons is high in Group 2 (NLR >2.05) and is statistically significant $(P=0.021)$. We report that the increased obsCAD found in high NLR group is important because of its potential danger in future to cause myocardial infarction.

Some studies show that prediabetic condition is associated with increased cardiovascular risks. ${ }^{51}$ Additionally, these studies demonstrated that the impairment in early markers of atherosclerosis is responsible for this process. ${ }^{52,53}$ Insulin resistance is one of the important factor for shaping the future of T2DM patients. ${ }^{54}$ Newman et al emphasized that this is genetically determined and an important thing for the future of T2DM patients, and it has come out as family history. ${ }^{55}$ In our study, we found similar rates of T2DM family history.

\section{Study limitations}

The present study mostly comprised patients who underwent MSCT and are being prediagnosed with CAD. This study was designed as cross-sectional and retrospective. Thus, epidemiological studies are needed to verify the results of the present study. Since all the patients were Caucasian, the study does not represent other races. The diagnosis of CAD was performed only using MSCT. In some cases, there was difficulty in detecting the degree of obstruction in terms of $\mathrm{CAD}$, rarely in the event of massive calcified plaques on MSCT coronary angiography, although respiratory artifacts in the patients with respiratory distress caused difficulties in differentiation from likely coronary artery soft plaques.

\section{Conclusion}

In the present study, the rate of obsCAD was significantly higher in the T2DM patients with NLR $>2.05$ than those with 
$\mathrm{NLR} \leq 2.05$. In addition to CACS, obsCAD has the potential risk of ischemic CAD and is related to cardiac events in future, and it was also found to be significantly higher in the patients with NLR $>2.05$ than the patients with NLR $\leq 2.05$. According to our study, we can say that the T2DM persons who have high NLR value have the increased risk of ischemic CAD and cardiac events such as acute coronary syndrome and myocardial infarction.

The results of the present study conducted in T2DM patients can be summarized in two ways: first, rate of obsCAD is significantly higher in those with high NLR value, second, coronary calcium risk score, it is seen as the predictor of ischemic CAD, is increased in those with high NLR value. These results should be supported by further comprehensive studies.

\section{Disclosure}

The authors report no conflicts of interest in this work.

\section{References}

1. Zhang P, Zhang X, Brown J, et al. Global healthcare expenditure on diabetes for 2010 and 2030. Diabetes Res Clin Pract. 2010;87:293-301.

2. Grundy SM, Benjamin IJ, Burke GL, et al. Diabetes and cardiovascular disease: a statement for healthcare professionals from the American Heart Association. Circulation. 1999;100:1134-1146.

3. Libby P, Ridker PM, Maseri A. Inflammation and atherosclerosis. Circulation. 2002;105:1135-1143.

4. Yach D, Stuckler D, Brownell KD. Epidemiologic and economic consequences of the global epidemics of obesity and diabetes. Nat Med. 2006; 12:62-66.

5. Rydén L, Grant PJ, Anker SD, et al. ESC Guidelines on diabetes, prediabetes, and cardiovascular diseases developed in collaboration with the EASD: the task force on diabetes, pre-diabetes, and cardiovascular diseases of the European Society of Cardiology (ESC) and developed in collaboration with the European Association for the Study of Diabetes (EASD). Eur Heart J. 2013;34:3035-3087.

6. Cersosimo E, DeFronzo RA. Insulin resistance and endothelial dysfunction: the road map to cardiovascular diseases. Diabetes Metab Res Rev. 2006;22:423-436.

7. American Diabetes Association. Diagnosis and classification of diabetes mellitus. Diabetes Care. 2014;37(suppl 1):S81-S90.

8. Aroor AR, Mandavia CH, Sowers JR. Insulin resistance and heart failure: molecular mechanisms. Heart Fail Clin. 2012;8:609-617.

9. Zhang X, Chen C. A new insight of mechanisms, diagnosis and treatment of diabetic cardiomyopathy. Endocrine. 2012;41:398-409.

10. Aksakal E, Akaras N, Kurt M, et al. The role of oxidative stress in diabetic cardiomyopathy: an experimental study. Eur Rev Med Pharmacol Sci. 2011;15:1241-1246.

11. Watanabe K, Thandavarayan RA, Harima M, et al. Role of differential signaling pathways and oxidative stress in diabetic cardiomyopathy. Curr Cardiol Rev. 2010;6:280-290.

12. Maisch B, Alter P, Pankuweit S. Diabetic cardiomyopathy - fact or fiction? Herz. 2011;36:102-115.

13. Hansson GK. Inflammation, atherosclerosis, and coronary artery disease. N Engl J Med. 2005;352:1685-1695.

14. Ross R. Atherosclerosis - an inflammatory disease. NEngl J Med. 1999; 340:115-126.

15. Hoffman M, Blum A, Baruch R, Kaplan E, Benjamin M. Leukocytes and coronary heart disease. Atherosclerosis. 2004;172:1-6.
16. Rana JS, Boekholdt SM, Ridker PM, et al. Differential leukocyte count and the risk of future coronary artery disease in healthy men and women: the EPIC-Norfolk Prospective Population Study. J Intern Med. 2007;262:678-689.

17. Giugliano G, Brevetti G, Lanero S, Schiano V, Laurenzano E, Chiariello M. Leukocyte count in peripheral arterial disease: a simple, reliable, inexpensive approach to cardiovascular risk prediction. Atherosclerosis. 2010;210:288-293.

18. Gibson PH, Cuthbertson BH, Croal BL, et al. Usefulness of neutrophil/ lymphocyte ratio as predictor of new-onset atrial fibrillation after coronary artery bypass grafting. Am J Cardiol. 2010;105:186-191.

19. Akyel A, Yayla Ç, Erat M, et al. Neutrophil-to-lymphocyte ratio predicts hemodynamic significance of coronary artery stenosis. Anatol J Cardiol. Epub 2015 Apr 2.

20. Verdoia M, Barbieri L, Giovine GD, et al; Novara Atherosclerosis Study Group (NAS). Neutrophil to lymphocyte ratio and the extent of coronary artery disease: results from a large cohort study. Angiology. Epub 2015 Mar 29.

21. Soylu K, Nar G, Aksan G, et al. Serum neutrophil gelatinase-associated lipocalin levels and aortic stiffness in noncritical coronary artery disease. Cardiorenal Med. 2014;4:147-154.

22. Moro-García MA, López Iglesias F, Avanzas P, et al. Disease complexity in acute coronary syndrome is related to the patient's immunological status. Int J Cardiol. 2015;189:115-123.

23. Bolick LE, Blankenhorn DH. A quantitative study of coronary arterial calcification. Am J Pathol. 1961;39:511-519.

24. Stanford W, Thompson BH. Imaging of coronary artery calcification: its impotance in assesing atherosclerotic disease. Radiol Clin North Am. 1999;37:257-272.

25. Nieman K, van der Lugt A, Pattynama PM, de Feyter PJ. Noninvasive visualization of atherosclerotic plaque with electron beam and multislice spiral computed tomography. J Interv Cardiol. 2003;16: 123-128.

26. Jakobs TF, Wintersperger BJ, Herzog P, et al. Ultra-low-dose coronary artery calcium screening using multislice CT with retrospective ECG gating. Eur Radiol. 2003;13:1923-1930.

27. Motoyama S, Kondo T, Anno H, et al. Atherosclerotic plaque characterization by 0.5 -mm-slice multislice computed tomo graphic imaging. Circ J. 2007;71:363-366.

28. Jinzaki M, Sato K, Tanami Y, et al. Novel method of displaying coronary CT angiography: angiographic view. Circ J. 2006;70: 1661-1662.

29. Reiner Z, Catapano AL, Backer GD, et al; ESC Committee for Practice Guidelines (CPG) 2008-2010 and 2010-2012 Committee. The Task for the management of dyslipidaemias of the European Society of Cardiology (ESC) and the European Atherosclerosis Society (EAS). Eur Heart J. 2011;32:1769-1818.

30. Nasir K, Raggi P, Rumberger JA, Budoff MJ, Blumenthal RS. Electron beam tomography in women. Is it a valuable test? Cardiol Rev. 2005;13: 174-183.

31. Imazeki T, Sato Y, Inoue F, et al. Evaluation of coronary artery remodeling in patients with acute coronary syndrome and stable angina by multislice computed tomography. Circ J. 2004;68:1045-1050.

32. Leschka S, Alkadhi H, Plass A, et al. Accuracy of MSCT coronary angiography with 64-slice technology: first experience. Eur Heart J. 2005;26:1482-1487.

33. Budoff MJ, Gul KM. Expert review on coronary calcium. Vasc Health Risk Manag. 2008;4:315-324.

34. Sarwar A, Shaw LJ, Shapiro MD, et al. Diagnostic and prognostic value of absence of coronary artery calcification. JACC Cardiovasc Imaging. 2009;2:675-688.

35. Budoff MJ, Diamond GA, Raggi P, et al. Continuous probabilistic prediction of angiographically significant coronary artery disease using electron beam tomography. Circulation. 2002;105:1791-1796.

36. Drechsler M, Megens RT, van Zandvoort M, Weber C, Soehnlein O, et al. Hyperlipidemia-triggered neutrophilia promotes early atherosclerosis. Circulation. 2010;122:1837-1845. 
37. Ganguli D, Das N, Saha I, et al. Association between inflammatory markers and cardiovascular risk factors in women from Kolkata, W.B, India. Arq Bras Cardiol. 2011;96:38-46.

38. Tian N, Penman AD, Mawson AR, Manning RD Jr, Flessner MF. Association between circulating specific leukocyte types and blood pressure: the atherosclerosis risk in communities (ARIC) study. $\mathrm{J} \mathrm{Am}$ Soc Hypertens. 2010;4:272-283.

39. Furman MI, Becker RC, Yarzebski J, Savegeau J, Gore JM, Goldberg RJ. Effect of elevated leukocyte count on in-hospital mortality following acute myocardial infarction. Am J Cardiol. 1996;78:945-948.

40. Kirtane AJ, Bui A, Murphy SA, Barron HV, Gibson CM. Association of peripheral neutrophilia with adverse angiographic outcomes in ST-elevation myocardial infarction. Am J Cardiol. 2004;93:532-536.

41. Thomson SP, Gibbons RJ, Smars PA, et al. Incremental value of the leukocyte differential and the rapid creatine kinase-MB isoenzyme for the early diagnosis of myocardial infarction. Ann Intern Med. 1995;122: 335-341.

42. Papa A, Emdin M, Passino C, Michelassi C, Battaglia D, Cocci F. Predictive value of elevated neutrophil-lymphocyte ratio on cardiac mortality in patients with stable coronary artery disease. Clin Chim Acta. 2008;395:27-31.

43. Horne BD, Anderson JL, John JM, et al; Intermountain Heart Collaborative Study Group. Which white blood cell subtypes predict increased cardiovascular risk? J Am Coll Cardiol. 2005;45:1638-1643.

44. Gibson PH, Croal BL, Cuthbertson BH, et al. Preoperative neutrophillymphocyte ratio and outcome from coronary artery bypass grafting. Am Heart J. 2007;154:995-1002.

45. Duffy BK, Gurm HS, Rajagopal V, Gupta R, Ellis SG, Bhatt DL. Usefulness of an elevated neutrophil to lymphocyte ratio in predicting long-term mortality after percutaneous coronary intervention. Am J Cardiol. 2006;97:993-996.

46. Kalay N, Dogdu O, Koc F, et al. Hematologic parameters and angiographic progression of coronary atherosclerosis. Angiology. 2012;63: 213-217.
47. Azab B, Chainani V, Shah N, McGinn JT. Neutrophil-lymphocyte ratio as a predictor of major adverse cardiac events among diabetic population: a 4-year follow-up study. Angiology. 2013;64:456-465.

48. Balta S, Celik T, Mikhailidis DP, et al. The relation between atherosclerosis and the neutrophil-lymphocyte ratio. Clin Appl Thromb Hemost. 2015;56(1):18-21.

49. Kurtul S, Sarli B, Baktir AO, et al. Neutrophil to lymphocyte ratio predicts SYNTAX score in patients with non-ST segment elevation myocardial infarction. Int Heart J. 2015;56:18-21.

50. Tsai JC, Sheu SH, Chiu HC, et al. Association of peripheral total and differential leukocyte counts with metabolic syndrome and risk of ischemic cardiovascular diseases in patients with type 2 diabetes mellitus. Diabetes Metab Res Rev. 2007;23:111-118.

51. Balkau B, Shipley M, Jarrett RJ, et al. High blood glucose concentrations is a risk factor for mortality in middle-aged nondiabetic men. 20-year follow-up in the Whitehall Study, the Paris Prospective Study, and the Helsinki Policemen Study. Diabetes Care. 1998;21:360-3677.

52. Jaap AJ, Hammersley MS, Shore AC, Tooke JE. Reduced microvascular hyperaemia in subjects at risk of developing type 2 (noninsulindependent) diabetes mellitus. Diabetologia. 1994;37:214-216.

53. Williams SB, Goldfine AB, Timimi FK, et al. Acute hyperglycemia attenuates endothelium-dependent vasodilation in humans in vivo. Circulation. 1998;97:1695-1701.

54. Kriketos AD, Greenfield JR, Peake PW, et al. Inflammation, insulin resistance, and adiposity: a study of firstdegree relatives of type 2 diabetic subjects. Diabetes Care. 2004;27:2033-2040.

55. Newman B, Selby JV, King MC, Slemenda C, Fabsitz R, Friedman GD Concordance for type 2 (non-insulin-dependent) diabetes mellitus in male twins. Diabetologia. 1987;30(10);763-768.
Patient Preference and Adherence

\section{Publish your work in this journal}

Patient Preference and Adherence is an international, peer-reviewed, open access journal that focuses on the growing importance of patient preference and adherence throughout the therapeutic continuum. Patient satisfaction, acceptability, quality of life, compliance, persistence and their role in developing new therapeutic modalities and compounds to optimize

\section{Dovepress}

clinical outcomes for existing disease states are major areas of interest for the journal. This journal has been accepted for indexing on PubMed Central. The manuscript management system is completely online and includes a very quick and fair peer-review system, which is all easy to use. Visit http://www. dovepress.com/testimonials.php to read real quotes from published authors. 